\title{
Shear-Strengthening of Reinforced \& Prestressed Concrete Beams Using FRP: Part II - Experimental Investigation
}

\author{
Thomas H.-K. Kang ${ }^{1) * *}$ and Moustapha Ibrahim Ary ${ }^{2)}$
}

\begin{abstract}
The main objectives of this research were to experimentally evaluate the impact of Carbon Fiber-Reinforced Polymers (CFRP) amount and strip spacing on the shear behavior of prestressed concrete (PC) beams and to evaluate the applicability of existing analytical models of Fiber-Reinforced Polymer (FRP) shear capacity to PC beams shear-strengthened with CFRP. The Ushaped CFRP strips with different spacing were applied externally to the test specimens in order to observe the overall behavior of the prestressed concrete I-beams and the mode of failure of the applied CFRP strips. Results obtained from the experimental program showed that the application of CFRP strips to prestressed concrete I-beams did in fact enhance the overall behavior of the specimens. The strengthened specimens responded with an increase in ductility and in shear capacity. However, it should be noted that the CFRP strips were not effective at all at spacing greater than half the effective depth of the specimen and that fracture of the strips was the dominant failure mechanism of CFRP. Further research is needed to confirm the conclusion derived from the experimental program.
\end{abstract}

Keywords: FRP, prestressed concrete, shear, strengthening, rehabilitation.

\section{Introduction}

Fiber-Reinforced Polymers (FRP) are composite systems of fibers embedded in a polymeric matrix. ${ }^{1}$ The polymer used is usually epoxy resin mixed with a hardener for workability. Rehabilitation of reinforced concrete (RC) members using FRP has been practiced by engineers for many years. ${ }^{2}$ Carbon Fiber Reinforced Polymers (CFRP) are widely used in civil engineering applications due to their high strength-to-weight ratio and rigidity. Various studies conducted by academic researchers have shown that the application of CFRP for retrofit or repair increases the overall shear or flexural capacity of deficient structural members. ${ }^{3}$ However to date, due to the complex nature of the interaction between CFRP and concrete members, no accurate and comprehensive models for the prediction of the shear strength contribution by CFRP are available.

In this research, an experimental program is devised to investigate the shear resistance of CFRP externally bonded to prestressed concrete I-beams without transverse reinforcement. No experimental tests have been conducted on prestressed concrete beams shear-strengthened with CFRP but without internal steel transverse reinforcement. The absence of transverse reinforcement could help to exclude the effects of steel transverse reinforcement. Furthermore, to the writers' knowledge, few I-shaped beams with

\footnotetext{
${ }^{1)}$ KCI Member, Department of Architecture and Architectural Engineering, Seoul National University, Seoul 151-744, Korea.

*Corresponding Author; E-mail: tkang@snu.ac.kr

${ }^{2)}$ School of Civil Engineering and Environmental Science, University of Oklahoma, Norman, OK 73019, USA.

Copyright (c) 2012, Korea Concrete Institute. All rights reserved, including the making of copies without the written permission of the copyright proprietors.
}

CFRP shear reinforcement have been tested.

The experimental program is also intended to observe the bond mechanism between the CFRP sheet and the concrete. All experimental beams are specially designed to fail in shear in order to better study the interaction between the concrete and the externally applied CFRP sheets. Results obtained from the experimental program do not only expand the relatively small database currently available on CFRP shear-strengthening, but also help improve existing analytical models by evaluating and identifying new key parameters. Understanding the interaction between CFRP and concrete helps improve existing analytical models and obtain a better estimation of the shear strength added by the CFRP. Considering the current database of CFRP strengthened beams, more data derived from large-scale specimen testing are needed in order to account for the scale effect and provide a better prediction of the behavior of externally applied CFRP sheets. Specific experiments designed to capture bond and anchorage issues are also needed to better predict the added shear capacity of the CFRP.

\section{Hypotheses and objectives}

The general goals of this research are: 1) to study the shear behavior of prestressed concrete I-beams strengthened with CFRP; 2) to quantify the added shear capacity of the CFRP; 3 ) to examine applicability of available analytical models to prestressed concrete I-beams; and 4) to define an optimal CFRP strengthening scheme for prestressed concrete I-beams. Aiming at these goals, three prestressed concrete I-beams were designed such that a shear failure was induced to the beams in a predetermined shear span, and the increase in shear capacity due to the application of CFRP was measured. The test specimens in this experimental study were strengthened with external strips of U-wrapped CFRP at different 
spacing. It is hypothesized that strengthening the prestressed concrete members with CFRP increases the overall shear capacity of the members.

\section{Experimental program}

\subsection{Specimen design}

In order to see the effects of the added shear capacity of CFRP, a total of three prestressed concrete I-beams were designed. All beams were designed to fail in shear in a specific shear span area. The guidelines in ACI 318-08, ${ }^{8}$ Building Code Requirements for Structural Concrete, were used to ensure that the test specimens reflect real-world prestressed concrete I-beams. As mentioned in Section 18.7.2 of ACI $318-08^{8}$, the alternative method to the more accurate determination (based on the strain compatibility) of the stress $\left(f_{p s}\right)$ in prestressing steel at nominal flexural strength was used. This alternative method determines an approximate value of $f_{p s}$ based on the assumption that the effective stress $\left(f_{s e}\right)$ in prestressing steel (after allowance for all prestress losses) shall not be less than $0.5 f_{p u}$ (specified tensile strength of prestressing steel). For members with bonded tendons, the stress in prestressing steel at nominal flexural strength is defined as:

$$
f_{p s}=f_{p u}\left\{1-\frac{\gamma_{p}}{\beta_{1}}\left[\rho_{p} \frac{f_{p u}}{f_{c}^{\prime}}+\frac{d}{d_{p}}\left(\omega-\omega^{\prime}\right)\right]\right\}
$$

where $\omega$ is the tension reinforcement index, $\omega^{\prime}$ is the compression reinforcement index, $d$ is the effective depth for nonprestressed mild steel, $d_{p}$ is the distance from extreme compression fiber to centroid of prestressing steel, $f_{p u}$ is the specified tensile strength of prestressing steel, $f_{c}^{\prime}$ is the specified compressive strength of concrete, $\rho_{p}$ is the ratio of prestressing tendons $\left(=A_{p s} / b d_{p}\right), A_{p s}$ is the prestressing steel area, $b$ is the width of compression face of the member, $f_{p s}$ is the stress in prestressing steel at nominal flexural strength, $\beta_{l}$ is the factor relating the depth of the equivalent rectangular compressive stress block to the neutral axis depth, and $\gamma_{p}$ is the factor for type of prestressing steel.

The nominal moment capacity and the corresponding ultimate load that the beam can carry were computed. All test specimens had a shear span-to-depth ratio $\left(a^{\prime} / d_{p}\right)$ of 2.5 . The chosen shear span-to-depth ratio of 2.5 ensures that a large shear-to-moment ratio is applied and the beams are expected to fail in shear as opposed to flexural failure. No stirrups were provided in the shear span zone. The nominal moment capacity of the beam was computed as follows:

$$
M_{n}=A_{p w} f_{p s}\left(d_{p}-\frac{a}{2}\right)+A_{s} f_{y}\left(d-d_{p}\right)+0.85 f_{c}^{\prime}\left(b-b_{w}\right) h_{f}\left(d_{p}-\frac{h_{f}}{2}\right)
$$

$$
A_{p w} f_{p s}=A_{p s} f_{p s}+A_{s} f_{y}-0.85 f_{c}^{\prime}\left(b-b_{w}\right) h_{f}
$$

where $M_{n}$ is the nominal moment capacity, $f_{p s}$ is the stress in prestressing steel at nominal flexural strength, $A_{p s}$ is the area of prestressing steel in the flexural tension zone, $a$ is the depth of the equivalent rectangular stress block, $A_{s}$ is the area of nonprestressed longitudinal tension reinforcement, $f_{y}$ is the specified yield strength of reinforcement, $b_{w}$ is the web width, and $h_{f}$ is the flange thickness.

The shear capacity of the beam was estimated in accordance with Section 11.3.2 of ACI 318-08, ${ }^{8}$ which specifies the concrete shear capacity $\left(V_{c}\right)$. The nominal shear capacity of the beams is defined as the sum of the shear contribution by the concrete and the steel transverse reinforcement. However, since no transverse reinforcement was provided in the shear span of interest (test span), the shear capacity in that region was only from the shear contribution of the concrete.

To ensure that the test specimens failed in shear before flexural yielding, while also keeping the under-reinforced aspect of the beam, reinforcing bars were used in the specimen design. Two \#6 longitudinal reinforcing bars with a clear cover of $1.63 \mathrm{in}$. and two \#8 bars with a clear cover of 4 in. were placed at the tension face of the specimens, and the two prestressing strands were located at a clear cover of $1.75 \mathrm{in.}$ On the compression face of the specimen, two \#4 bars were placed at a clear cover of $1.5 \mathrm{in}$. to enhance the overall ductility of the specimen. The \#3 bars were used for the stirrups only in the constant moment region (outside the shear span). Note also that all three test specimens were identical (same cross-section, reinforcement and dimensions), except for the FRP strengthening details. Figure 1 shows a detailed cross-sectional view of the specimens and Figure 2 shows an elevation and a top view of the beams. All dimensions are in inches.

\subsection{Test setup and specimen preparation}

All specimens were manufactured at Coreslab Structures Inc. in Oklahoma City, Oklahoma, and tested in the Donald G. Fears Structural Engineering Laboratory at the University of Oklahoma. An automated hydraulic actuator having a load capacity of 500

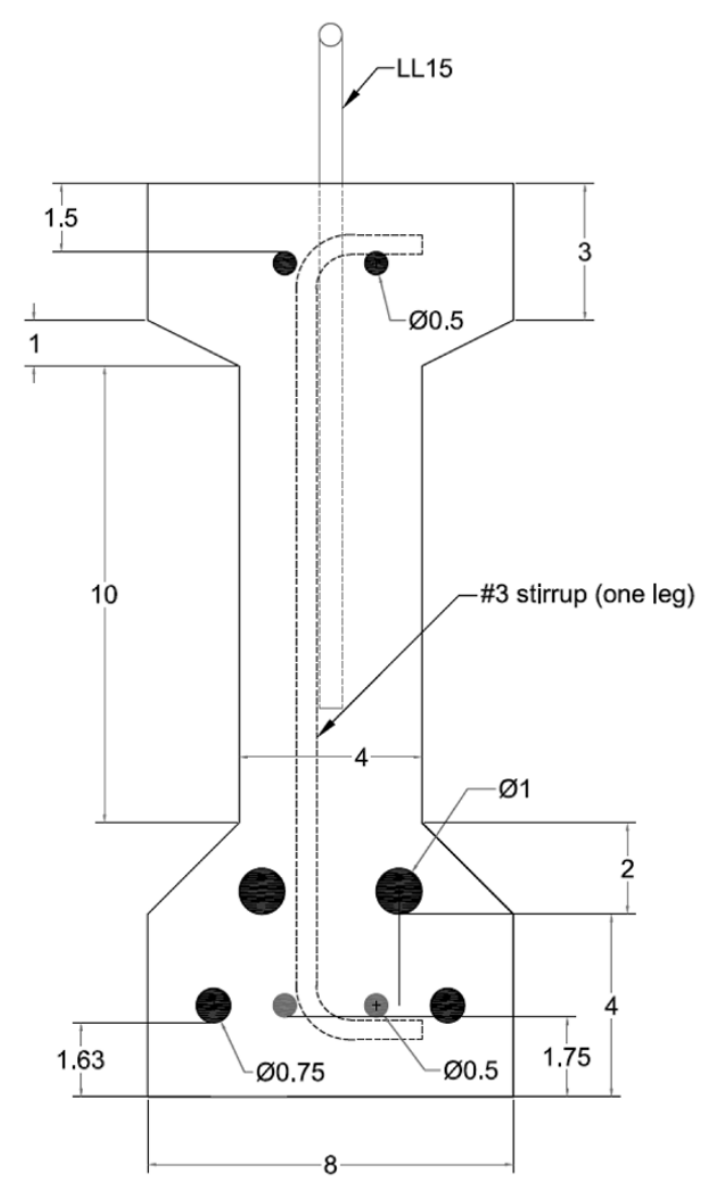

Fig. 1 Cross-sectional view of test specimen (Unit: in.). 
kips was used to test all three specimens. The specimens were simply supported and were tested under a four-point loading system via a spreader beam. Two small rollers, located at 45 in. from the supports, were placed at the contact point between the spreader beam and the test specimens. The rollers were placed on top of the specimens in order to induce the two point loads. The hydrostone was used between the test specimens and the steel bearing plate of the rollers to evenly distribute the load. The supports of the specimens were located at a distance of $90 \mathrm{in}$. from the mid-span and at $12 \mathrm{in.}$ from the end of the test beam. One end of the beam was placed on a roller support to allow beam expansion under loading while the other end was placed on a fixed support. One 100 kip and one $500 \mathrm{kip}$ load cell transducer were used in order to accurately measure the load induced by the hydraulic actuator. The load cell was put on a swivel to reduce the risk of eccentrically loading the spreader beam which transfers the load to the test specimens. A monotonic quasi-static loading was applied for all specimens.

Six wire potentiometers (WPs) were used to measure the linear vertical displacement of the specimens. The WPs, placed at both faces of the specimens, were located at each of the application points of the two-point loads and also at the mid-section of the specimen. The WP data were used to generate a load versus deflection curve, which was later used to investigate the shear behavior of the specimens.

In order to make the CFRP placement easier, the test beams were flipped upside down and pre-fit markings were drawn on the beam to make sure that the carbon fabric was being placed at the specified locations. A 360 in. by 42 in. roll of carbon fabric shipped from Fabric Development Inc. was used to strengthen the specimens. It is a multidirectional carbon fabric with a $24 \times 23$ fiber count per inch squared. The roll of carbon fabric was cut into strips $53 \mathrm{in}$. long and $3 \mathrm{in}$. wide that would be placed on the test specimens. The wet method was used to apply the carbon fabric to the test beams. In this method, the surface of the beams was checked for any irregularities that might alter the adhesion of the epoxy mix and then a first heavy coat of epoxy and hardener mix was rolled on the surface of the beams. The carbon fabric was then positioned in the pre-fit markings on the beam and unrolled onto the surface of the beams. A second coat of epoxy mix was then applied with a foam roller on top of the fabric and any excess epoxy was trimmed off with a plastic spreader. The epoxy and hardener used were obtained from West System, a major supplier of epoxy resin and hardeners in Oklahoma. The West System 105 epoxy resin and West System 205 hardener were used throughout the experimental program. The 205 hardener had a pot life of 9 to 12 minutes, a working time of 60 to 70 minutes and a cure time of 6 to 8 hours. All test specimens had cured at least 48 hours before being placed on the reaction frame for shear testing.

One beam, labeled as the control beam, was tested in shear in the loading frame. The control beam was painted in white and a 5 in. by 5 in. grid was drawn to locate the shear cracks at failure. No CFRP was applied to the control beam. The second beam, labeled as IB-10, was strengthened with U-wrapped CFRP strips spaced at $10 \mathrm{in}$. across the shear zone. The final beam, labeled IB-05, was also strengthened with CFRP strips but with strip spacing of 5 in. Figure 2 shows the test setup of the beam.

\subsection{Material testing}

Material properties were obtained using the corresponding American Standards for Testing Materials (ASTM). The tensile yield strength of reinforcement bars was obtained using guidelines in ASTM E8/E8M-09, ${ }^{9}$ Standard Test Methods for Tension Testing of Metallic Materials. Reinforcing bar samples of $4 \mathrm{ft}$ in length were used to determine the yield strength of the steel used in the test beams. All reinforcing bar samples were machined (ground down) at the midsection to allow for a localized failure or necking in a specified gauge length of 4 in. The specimens were ground to not less than $90 \%$ of their original cross sectional area as mandated by the ASTM. An extensometer was used to measure the
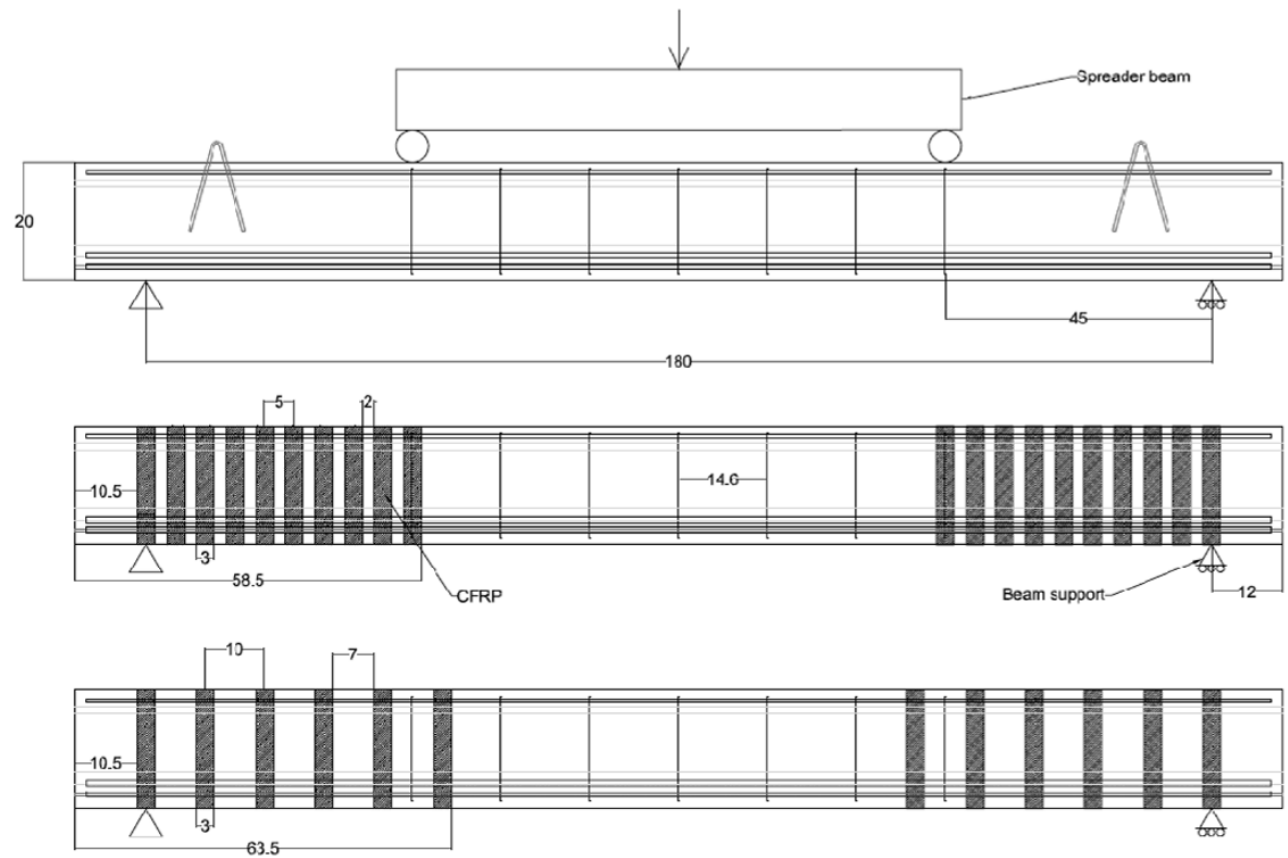

Fig. 2 Elevation view and applied CFRP configurations for test specimens (Unit: in.; left pin end: south end; right roller end; north end). 


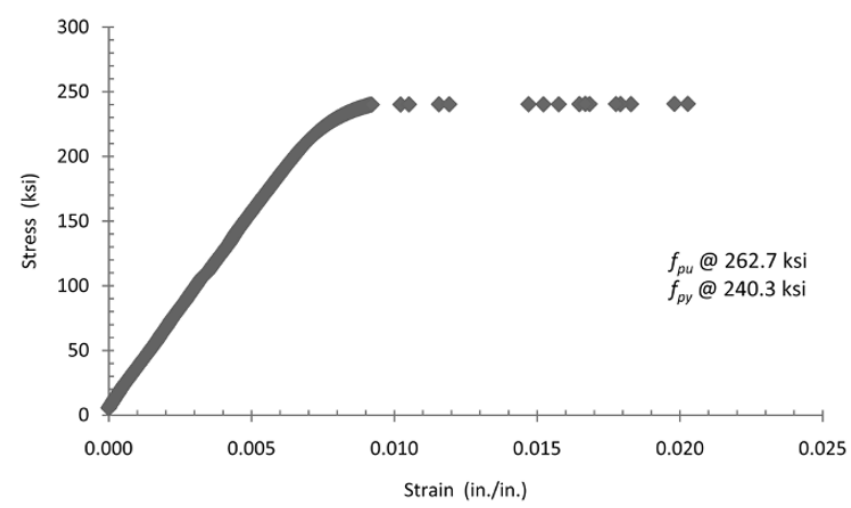

Fig. 3 Stress-strain curve for representative seven-wire strand.

strain of the bar samples under tensile loading. Wedge grips were used along with the Baldwin machine to apply the uniaxial load.

The extensometer was removed when the test specimen reached yielding. The ultimate strength of the rebar was later calculated from the load on the Baldwin machine.The yield strength of the steel reinforcing bar was found from the stress-strain relationship where the stress remained constant after a given strain. The ultimate strength of the specimen was determined by dividing the failure load by the machined area of the sample.

The same ASTM E8/E8M- $09^{9}$ specifications were used to determine the yield strength and ultimate strength of the $0.5 \mathrm{in}$. special seven-wire strand used to prestress the beams. Note that this special strand has a cross-sectional area different from that of typical 0.5 in. diameter seven-wire strand. Figure 3 shows the representative stress-strain curve for the strand.

The compressive strength of concrete was determined using ASTM C39/C39M-10, StandardTest Method forCompressive Strength of Cylindrical Concrete Specimens. A 6 in. diameter concrete cylinder was put between two bearing plates with bonded pads and placed on the Forney machine. The axial load from the Forney machine was applied at an acceptable rate until failure. The failure load was then divided by the measured cross sectional area of the cylinder to determine the compressive strength of the concrete. A strain gauge was used to measure the strain in the concrete cylinder. Figure 4 shows the stress-strain curve for one of the test cylinders.

The flexural strength of concrete was determined using ASTM C78/C78M-10, Standard Test Method for Flexural Strength of Concrete (Using Simple Beam withThird-Point Loading). A 6 in.

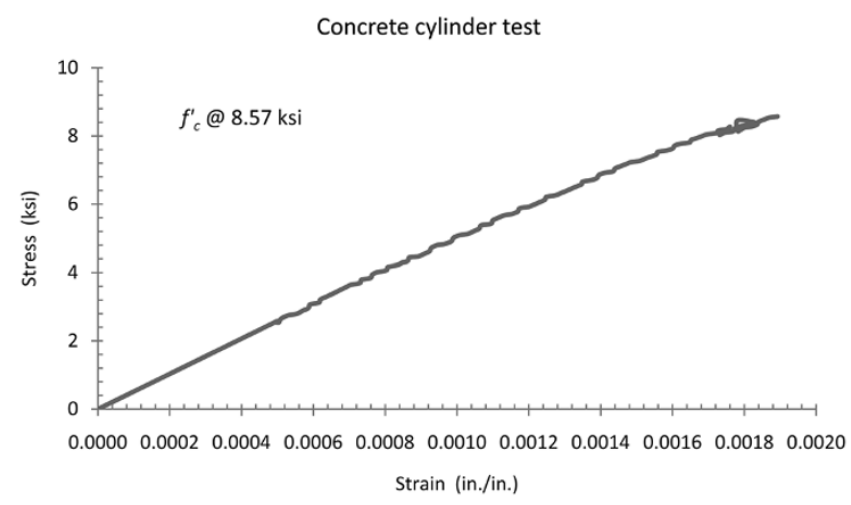

Fig. 4 Stress-strain curve for representative concrete cylinder.

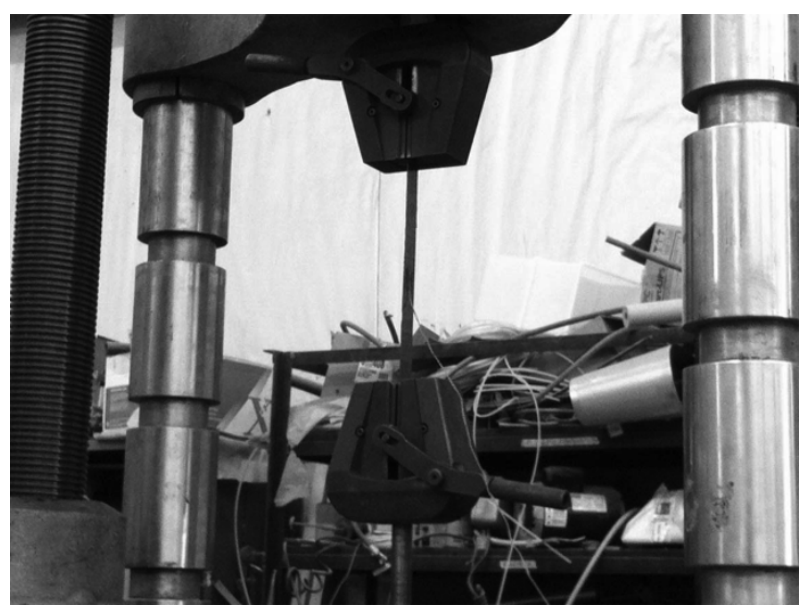

Fig. 5 CFRP tensile test setup.

deep, 6 in. wide and 18 in. long prism was cast to measure the Modulus of Rupture (MOR) of the concrete. TwoLinear Variable Differential Transformers (LVDTs) were used to measure the linear displacement of the prism. The prism was put on the Forney machine with a third point bending setup.

ASTM D3039/D3039M, Standard Test Method for Tensile Properties of Polymer Matrix Composite Material, was used to determine the actual strength of FRP used in the experimental program. The CFRP strips 2 in. wide and 16 in. long (including 3 in. grips on each end) were fabricated using the same epoxy and hardener used for the test beams. A total of 5 CFRP strips were tested in order to get an average tensile strength of the CFRP. The strips were placed on the Baldwin machine and wedges with flat grips were used to apply the uniaxial tensile load (Figure 5). The test CFRP strips used had an average thickness between 0.04 in. and $0.055 \mathrm{in}$. A strain gauge was placed at the mid-section of the strip sample to record the strain induced to the strip during tensile loading. Table 1 summarizes the material test results. All the data for the materials are available elsewhere. ${ }^{4}$

\section{Test results and discussion}

\subsection{Results}

All three prestressed test specimens were subjected to a fourpoint loading system and failed as expected in a shear failure. The specimens showed diagonal shear cracks that initiated from the

Table 1 Average material property data.

\begin{tabular}{c|c|c|c|c|c|c|c|c}
\hline Material & $t_{f}$ (in.) & $f_{c}^{\prime}(\mathrm{psi})$ & $E_{f}(\mathrm{ksi})$ & $f_{r}(\mathrm{psi})$ & $\varepsilon_{f u}$ & $f_{u}(\mathrm{ksi})$ & $E(\mathrm{ksi})$ & $f_{y}(\mathrm{ksi})$ \\
\hline \hline CFRP & 0.049 & - & 955 & - & 0.015 & 14.32 & - & - \\
\hline Concrete & - & 8846 & - & 711 & - & - & 5702 & \\
\hline \#3 rebar & - & - & - & - & - & 101.4 & 28852 & 63.7 \\
\hline \#4 rebar & - & - & - & - & - & 103.2 & 27071 & 60.1 \\
\hline \#6 rebar & - & - & - & - & - & 111.1 & 29667 & 69.1 \\
\hline \#8 rebar & - & - & - & - & - & 109.1 & 27981 & 62.8 \\
\hline Strand & - & - & - & - & - & 264 & 29087 & 241 \\
\hline
\end{tabular}

$t_{f}=$ FRP thickness; $f_{c}^{\prime}=$ concrete compressive strength; $E_{f}=$ modulus of elasticity of FRP; $f_{r}=$ modulus of rupture of concrete; $f_{u}=$ ultimate strength; $E=$ modulus of elasticity; $f_{y}=$ yield strength of steel 
Table 2 Summary of experimental results.

\begin{tabular}{c|c|c|c|c|c|c}
\hline Specimen & Failure load (kip) & Shear load (kip) & $\begin{array}{c}\text { CFRP shear contri- } \\
\text { bution (kip) }\end{array}$ & Cracking load (kip) & $\begin{array}{c}\text { WP1 west deflec- } \\
\text { tion (in.) }\end{array}$ & CFRP failure type \\
\hline \hline Control beam & 52.8 & 26.4 & - & 39.64 & 0.496 & - \\
\hline IB-10 & 53.6 & 26.8 & 0.4 & 40.02 & 0.486 & Fracture \\
\hline IB-05 & 72.8 & 36.4 & 10 & 39.9 & 0.635 & Fracture \\
\hline
\end{tabular}

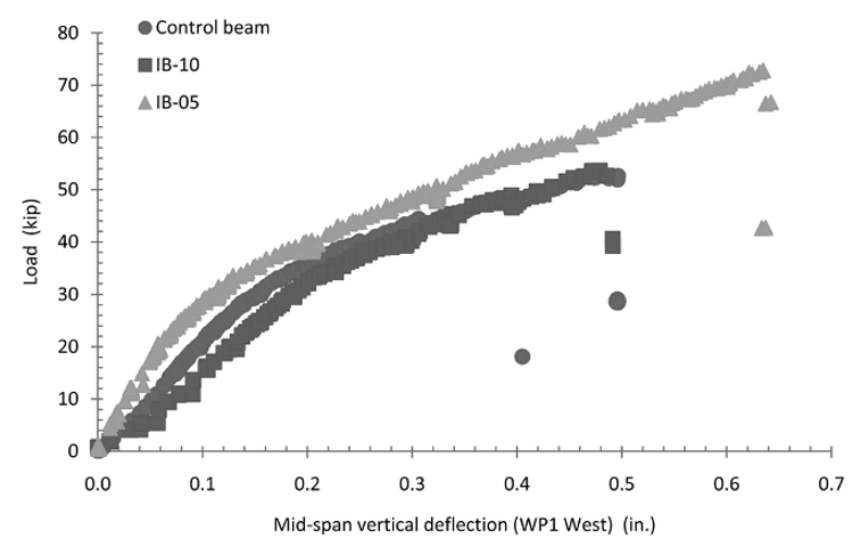

Fig. 6 Load versus mid-span deflection curves of tested beams.

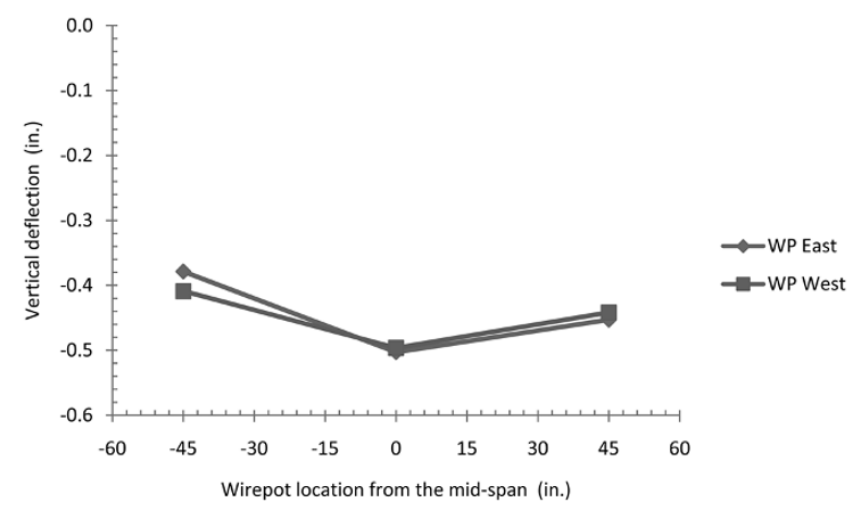

Fig. 7 Deflection profile of control beam at failure (negative location: south - WP3; positive location: north - WP2; center location - WP1).

supports up to the loading points. Shear cracks were marked as they appeared on the specimen along with the corresponding load during the test. The 100 kip load cell transducer was used during the control beam test and was later switched for the 400 kip load cell for the strengthened specimens test. The 400 kip load cell was used in order to protect the $100 \mathrm{kip}$ cell, and because preliminary calculations had predicted that the strengthened specimens would fail at loads close to 100 kips. The wire potentiometers (WP) placed at midsection and at loading points of the beam measured the vertical displacement at both east and west faces of the beam (i.e., front and back faces of the beam).Data from WP1 East in IB10 were compromised during testing, and as a consequence and for comparison reasons, no data from WP1 East located at the east face of the midsection on IB-10 were used in this project. Table 2 represents a summary of the results obtained during the experimental program.

Figure 6 shows the load versus mid-span deflection relations of the beams. Figure 7 shows the vertical displacement profile of the

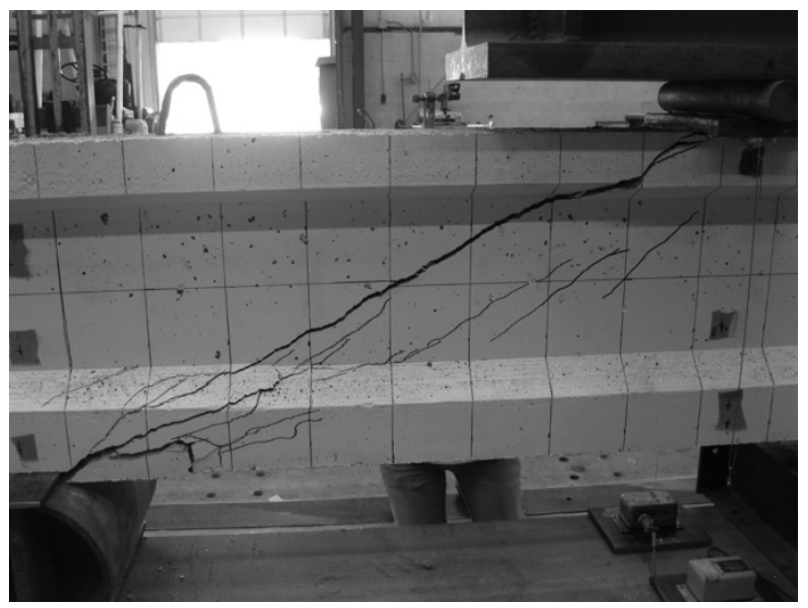

Fig. 8 Control beam shear cracks on the south end - east face.

control beam, where the data from two LVDTs on both sides of the beam are shown to be similar, and hence more reliable. Figure 8 shows the failure pattern for the control beam and the location of the shear cracks. The largest shear cracks were noticed at the south end of all tested specimens (refer to Figures 1, 7 and 8 for beam orientation). The control beam failed in shear with shear cracks propagating from the support to the loading point at an approximately $45^{\circ}$ angle. One large shear crack was developed at failure and smaller cracks started to show up at approximately 40 kips during the loading process. The ultimate load that the hydraulic actuator induced to the control beam was 52.8 kips which yielded a nominal shear capacity of 26.4 kips. Preliminary calculations had predicted a nominal shear capacity of 23 kips. As expected, the control beam failed in a brittle manner with the beam almost being split in half in the shear span. The largest vertical deflection was $0.5 \mathrm{in}$. and was recorded by WP1 West located at the west face of the midsection of the beam.

Specimen IB-10 strengthened by external CFRP strips at a spacing of $10 \mathrm{in}$. also failed as expected in shear with shear cracks propagating diagonally in the shear span area and through the CFRP strips (Figure 9). Concrete cracking occurred at around 40 kips as in the control beam (Figure 6). The beam was loaded in 5 kip increments until the first concrete cracking and then at 10 kip increments until the ultimate failure. The largest shear crack was located at the south end of the beam in the shear span area. The ultimate load carried by the beam was 53.6 kips (26.8 kips shear capacity). Upon failure, the CFRP strips were fractured along the same plane as the shear cracking. Only fracture and not debonding of the CFRP strips was observed. Concrete splitting in the shear span was also observed (Figure 9). Note that the CFRP strips failed in a brittle manner just like the beam itself. The maximum midsection deflection of the beam was 0.5 in. (recorded by WP1 West) and the maximum vertical deflection of 0.5 in. was also 


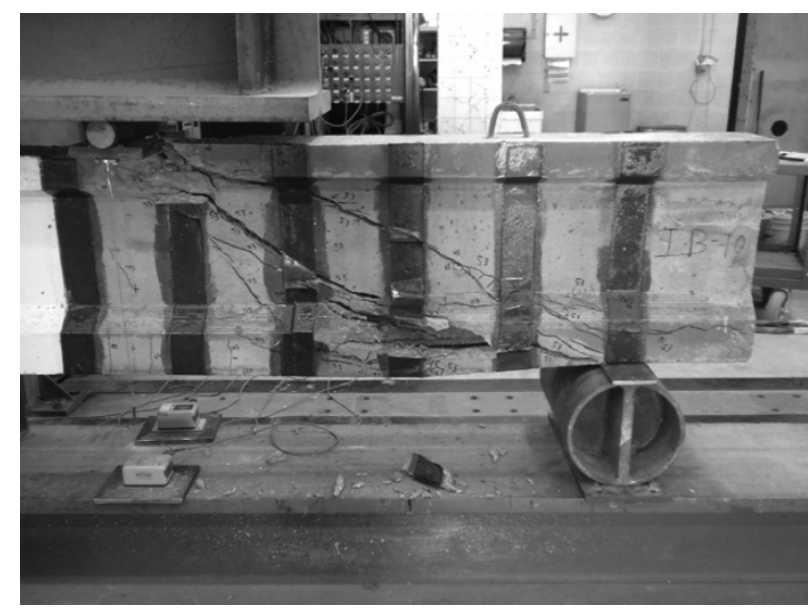

Fig. 9 Failure pattern and CFRP fracture of IB-10 (south end west face).

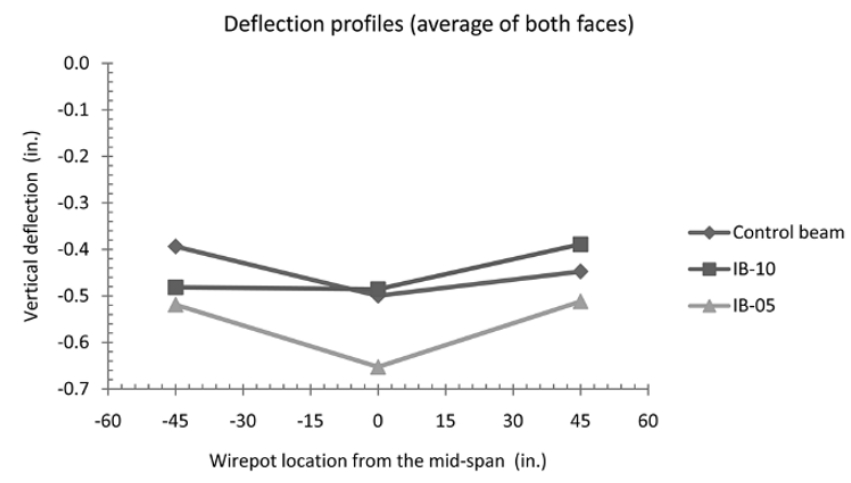

Fig. 10 Deflection profiles of tested beams at failure (negative location: south - WP3; positive location: north - WP2; center location - WP1).

recorded by WP3 East on the south end of the beam. Figure 10 shows the deflection profile of the beam, where the larger deflection was noted on the failed zone for IB-05.

Specimen IB-05 was also strengthened in shear with 3 in. wide CFRP strips spaced at 5 in. across the shear span. The first cracks on the concrete appeared at around 40 kips during loading (Figure 6). The specimen was also loaded in 5 kip increments until concrete cracking and then at $10 \mathrm{kip}$ increments until failure. The ultimate failure load recorded by the load cell transducer was 72.8 kips which yielded a maximum shear capacity of 36.4 kips. The CFRP strips were fractured at failure, with the exception of a few strips that debonded from the concrete cover (at angles) (Figure 11). Strain gauges were not attached; however, the visual inspection indicates that the CFRP appeared to be fully developed at either side of the shear crack where the facture of the CFRP occurred.Just like the previous two beams, the largest shear cracks were observed at the south end of the beam where the loss of

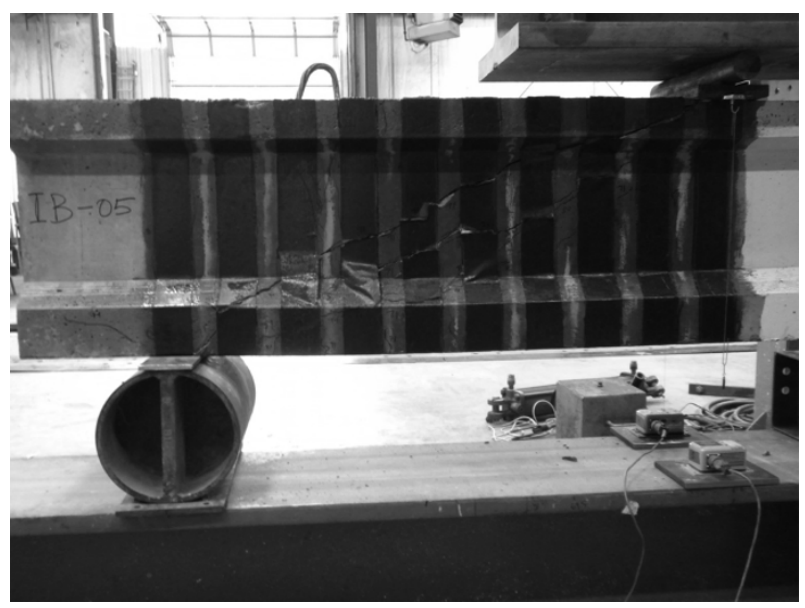

Fig. 11 Failure pattern and CFRP in IB-5 (south end - east face).

aggregate interlock occurred at failure. The midsection deflection was 0.635 in. (WP1 West), which was the largest recorded deflection on the beam, and among the beams (Figures 6 and 10).

\subsection{Behavior and failure mode of the specimens}

The essentially linear behavior of the beams was determined using the load versus displacement curve generated by the wire potentiometers and the load cell transducer. The added shear capacity $\left(V_{f}\right)$ due to external CFRP reinforcement was defined as the maximum shear capacity of the strengthened beam minus the shear capacity of the control beam. The resulting percent increase in shear capacity was calculated using Eq. (4) as shown below:

Increase in measured shear capacity due to CFRP (\%)

$$
=\frac{\left(V_{\text {specimen }}-V_{\text {control }}\right)}{V_{\text {control }}} \times 100
$$

where $V_{\text {specimen }}$ is the failure shear load of a tested specimen and $V_{\text {control }}$ is the failure shear load of the control beam. The increase in shear capacity $\left(V_{f}\right)$ with respect to the control beam was used to evaluate the effectiveness of the two strengthening schemes used to reinforce the test specimens. The external CFRP strips hardly impacted the cracking moment value of the specimens. All three beams (strengthened and non-strengthened) had an experimental cracking moment of about 900 kips-in., whereas theoretical estimation by ACI $318-08^{8}$ had predicted a cracking moment of 724 kips-in. The difference between the experimental and theoretical cracking moments can be attributed to material property variations (varied tensile strength, for instance).

A summary of the percent increase and added shear capacity along with the vertical deflection of the specimens is provided in Table 3. The load versus deflection curve in Figure 6 shows that IB-05 was much more ductile than IB-10 and the control beam.

Table 3 Shear increase and deflection comparisons.

\begin{tabular}{c|c|c|c|c|c|c|c}
\hline Specimen & Failure load (kip) & Shear load (kip) & $\begin{array}{c}\text { CFRP shear con- } \\
\text { tribution (kip) }\end{array}$ & $\begin{array}{c}\text { WP1 west deflec- } \\
\text { tion (in.) }\end{array}$ & $\begin{array}{c}\text { CFRP failure } \\
\text { type }\end{array}$ & $\begin{array}{c}\text { Increase in shear } \\
\text { capacity }\end{array}$ & $\begin{array}{c}\text { Deflection per- } \\
\text { cent difference }\end{array}$ \\
\hline \hline Control beam & 52.83 & 26.42 & - & 0.496 & - & - & - \\
\hline IB-10 & 53.64 & 26.82 & 0.4 & 0.486 & Fracture & $1.5 \%$ & $2.2 \%$ \\
\hline IB-05 & 72.83 & 36.42 & 10 & 0.635 & Fracture & $37.85 \%$ & $27.85 \%$ \\
\hline
\end{tabular}


Specimen IB-10 and the control beam had almost the same midsection vertical deflection up to failure. The external CFRP reinforcement applied to IB-10 did not help increase the vertical deflection of the beam. In contrast to the strengthening effect of IB-10, the CFRP strips in IB-05 increased the overall deflection of the beam. In fact, IB- 05 had a deflection value almost $28 \%$ higher than the control beam whereas IB-10 had an average deflection $2 \%$ less than that of the control beam. The experimental results obtained showed that the spacing of CFRP strips played a role in increasing the ductility of IB- 05 . Since spacing of the CFRP strips was the only different variable in the strengthened beams, it can be concluded that the spacing (10 in.) of the strips in IB-10 was not effective at all and that CFRP reinforcementwith relatively large strip spacing had negligible influence on the overall ductility of IB-10. Figure 10 shows the deflection profile for all three beams and shows the difference in ductility between IB-05 and the remaining two other specimens.According to the experimental results, the external CFRP strips applied to IB-10 did not generate any noticeable increase in either the shear capacity or the ductility of the specimen. The 3 in. wide CFRP strips applied externally to IB-10 and spaced at 10 in. center-to-center had a shear contribution of only 0.4 kips relative to the overall shear capacity of the beam. The beam had very similarly linear behavior with the control beam. This general behavior of IB-10 can be linked to the large spacing of the external CFRP strips. It appearsthatthe CFRP strips did not act as atensiontie due to the strip spacing which was greater than half the effective depth of the concrete beam. Note that the strips applied to IB- 10 were spaced at 10 in. intervals center-to-center while half the effective depth of the specimen was 8.4 in. On the other hand, specimen IB-05 showed a much more positive response in terms of the CFRP shear-strengthening; the experimental shear contribution due to CFRP strengthening was 10 kips. This is approximately a $38 \%$ increase in overall shear capacity compared to the control beam. The CFRP strips were only spaced at 5 in. center-to-center, which represents half of the strip spacing in IB-10.

The failure mode of CFRP in both IB-10 and IB-05 was mainly dominated by fracture of the strips at ultimate loads. Some CFRP strips in IB-05 debonded from the concrete at failure, but in general, fracture of the CFRP was the primary failure mode. The Ushaped CFRP reinforcement tends to have better anchorage to the concrete when it has an effective depth that extends all the way to the top compression fiber of a specimen, allowing for longer effective length for bonding compared with cases where the strip terminates below the flange. The effective depth of both prestressed specimens was the same as the effective depth of the external CFRP used.

Also, it should be noted that themeasured tensile strength of the

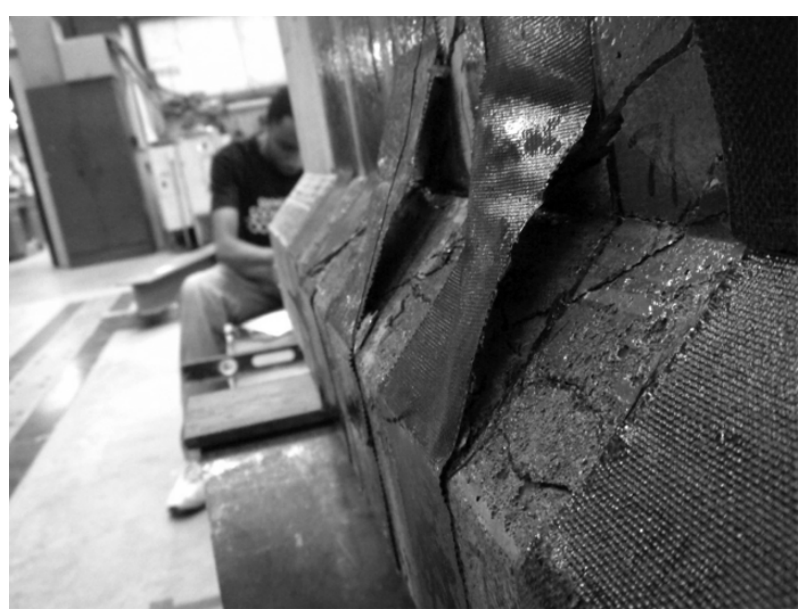

Fig. 12 Debonding at angle of IB-05.

carbon fiber sheet was quite a bit lower than expected, and consequently the amount of each CFRP strip turned out to be very small. This could be one more reason why most of the strips fractured at failure. The relatively small amount of the CFRP applied to the beam probably contributed to the full use of the tensile capacity of CFRP during shear loading.

The debonding of the strips at some locations was likely due to poor anchorage to the concrete cover which wascausedby the angle in the I-beams. Figures 11 and 12 show a detailed view of the debonding of CFRP at failure for IB-05. Note that debonding of the strips occurred at inside angles of the I-beam where proper anchorage is critical to avoid debonding.

\subsection{Analytical model prediction in relation to CFRP-strengthened prestressed concrete l-beams}

The analytical models assessed in the companion Part I paper ${ }^{3}$ were evaluated in this study for the prestressed concrete test specimens. The accuracy of the model was measured in comparison to the previous experimental results obtained during testing. ${ }^{4-7}$ It should be pointed out that even though the carbon fiber used was multidirectional, only the principal fiber orientation with respect to the longitudinal beam axis was used for theoretical CFRP shear estimation. The principal fiber direction extended to a length of roughly $53 \mathrm{in}$. and was oriented $90^{\circ}$ from the longitudinal beam axis while the minor fiber direction was only $3 \mathrm{in}$. and at $0^{\circ}$ relative to the beam axis. It was assumed that the minor fiber direction was negligible and did not contribute to any of the tensile strength of the strips and therefore did not contribute in the shear-strengthening of the specimens. Table 4 indicates the theoretical values derived from the analytical models along with the experimental values. Figure 13 shows a comparison between experimental

Table 4 Experimental and theoretical values of CFRP shear contribution.

\begin{tabular}{c|c|c|c|c|c|c|c|c|c}
\hline Specimen & $b_{w}$ (in.) & $d$ (in.) & CFRP Config. & $w_{f}$ (in.) & $s_{f}$ (in.) & $\alpha$ (deg) & $V_{f(\text { Exp.) }}($ kip) $)$ & $V_{f(\mathrm{ACI})}(\mathrm{kip})$ & $\begin{array}{c}V_{f(\mathrm{~T} \& \mathrm{~A} 2000)} \\
(\mathrm{kip})\end{array}$ \\
\hline \hline Control beam & 4 & 16.75 & - & - & - & - & - & - & - \\
\hline IB-10 & 4 & 16.75 & U-strips & 3 & 10 & 90 & 0.40 & 1.87 & 2.21 \\
\hline IB-05 & 4 & 16.75 & U-strips & 3 & 5 & 90 & 10.00 & 3.76 & 4.41 \\
\hline
\end{tabular}

$b_{w}=$ beam web width; $d=$ effective depth; $w_{f}=$ width of CFRP strip; $s_{f}=$ spacing between CFRP strips; $\alpha=$ angle of CFRP strip with respect to beam axis; $V_{f}=$ shear capacity of FRP. 


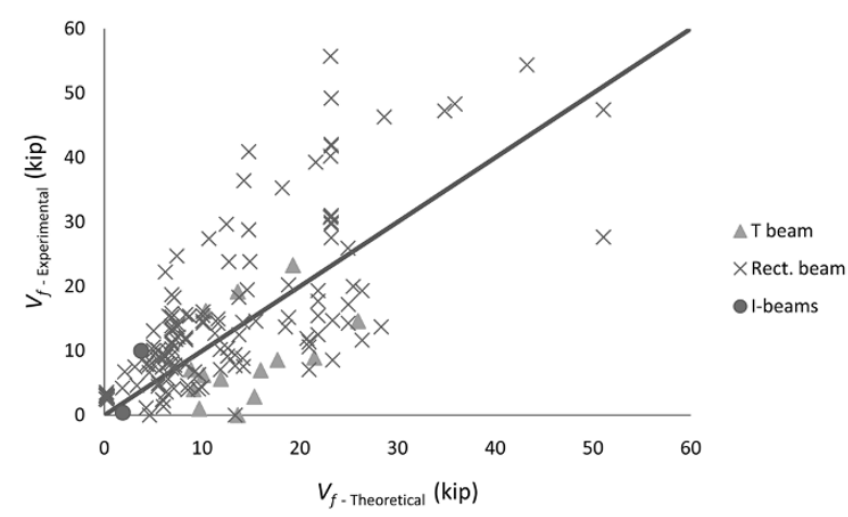

Fig. $13 \mathrm{ACl} 440$ model prediction for beams tested in this study (red circular dots) and in previous studies.

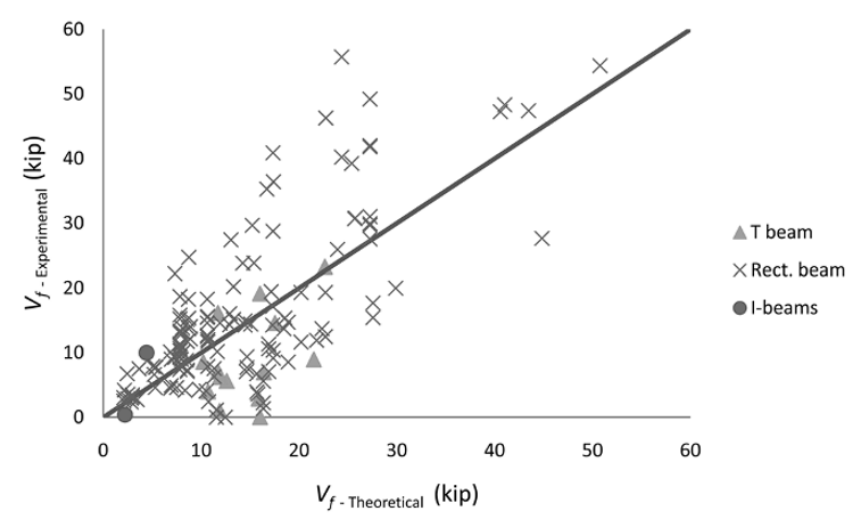

Fig. 14 Triantafillou and Antonopoulos model prediction for beams tested in this study (red circular dots) and in previous studies.

results obtained for FRP shear contribution and analytical model predictions by ACI 440.2R-08, and Figure 14 shows a similar comparison between the experimental data and the model developed by Triantafillou and Antonopoulos. ${ }^{5}$ The test specimen data are plotted along with previous data obtained from 157 concrete beams shear-strengthened with various FRP types. ${ }^{3}$

The added shear capacity of CFRP predicted by ACI 440.2R$08^{10}$ was 1.9 kips for IB-10 and 3.8 kips for IB- 05 . The ACI estimations, compared to the experimental results, underestimate the added shear capacity of CFRP by $62 \%$ for IB- 05 . It can be safe to assume that the ACI model prediction may not yield satisfactory results in the prediction of added shear capacity by CFRP applied externally to prestressed concrete I-beams, though the ACI $440^{10}$ model prediction is conservative in predicting the added shear capacity of CFRP in IB-05. The underestimation for the test results herein was attributed to the efficient use of CFRP until its fracture. This might have been possible because a relatively small amount of the CFRP was used to strengthen the shear capacity of the PC beam. The analytical model developed by Triantafillou and Antonopoulos $^{5}$ gives similar results. The estimations were 2.2 kips for IB-10 and 4.41 kips for IB-05. This analytical model also underestimates the experimentally measured shear capacity of the CFRP in IB- 05 by $56 \%$. It is noted that both models adopt the effective FRP strain concept. The effective FRP strains used in the models were significantly smaller than the measured ultimate strain (average $=0.01532$ ) of the CFRP in IB-05, which was the primary reason for the under-prediction of the measured CFRP shear capacity. Given the very small number of data available for PC (I-shaped) beams shear-strengthened with CFRP, more experimental tests would be necessary to confirm the effectiveness of CFRP in shear-strengthening prestressed concrete beams.

\section{Conclusions}

The experimental program conducted in the Donald G. Fears laboratory at the University of Oklahoma consisted of four-point load tests of two prestressed concrete I-beams with U-shaped CFRP strips and a companion prestressed concrete I-beam without CFRP shear reinforcement. The results have shown that the externally applied CFRP strips in prestressed concrete I-beams for shear-strengthening improved the overall shear capacity of the specimens, when the spacing was less than half the effective depth of the prestressed concrete beams. As such, the spacing of the strips used to reinforce the test specimen should be carefully planned, because spacing larger than half the effective depth hardly improved the shear behavior of the strengthened beam. On the other hand, spacing of CFRP strips less than half the effective depth has shown promising results. Also, such spacing has not only increased the ductility of the beam (IB- -05 ) by $28 \%$ but has also increased its shear capacity by $38 \%$ compared to the shear capacity of the control beam. Additionally, special attention should be paid to properly bond the CFRP and concrete at irregularly shaped locations such as the inside angle of an I-beam.

Both the ACI 440 prediction and the analytical model prediction by Triantafillou and Antonopoulos ${ }^{5}$ failed to provide a satisfactory estimation of the added shear contribution of CFRP applied to the tested prestressed concrete I-beams. This was because the predictions do not assume fracture of FRP strips, which however occurred in the current test program. Although the current test program provided very good information on the shear behavior of PC I-beams strengthened by externally bonded CFRP strips, for a better conclusion, more shear tests of PC beams strengthened by CFRP (by varied amounts) would be necessary.

\section{Acknowledgements}

The work presented in this paper was supported by U.S. DOTRITA grant under No. DTRT06-G-0016/OTCREOS10.1-21.The authors would like to thank the first author's undergraduate and graduate students, Deanna Quickle, Caroline Weston, Amy Hufnagel, Woosuk Kim, Colin Osborne and Chris Hill, for their assistance in the Donald G. Fears Structural Engineering Laboratory at the University of Oklahoma. The authors also acknowledge the active participation of Michael F. Daly, P.E. from Coreslab Structures, Inc. (OKLA), which provided all the prestressed concrete beams used in this study. The views expressed are those of the authors, and do not necessarily represent those of the sponsor.

\section{References}

1. Khalifa, A. and Nanni, A., "Rehabilitation of Rectangular Simply Supported RC Beams with Shear Deficiencies Using CFRP Composites," Construction and Building Materials, Vol. 16, No. 3, 2002, pp. 135-146. 
2. Kansara, K. D., Ibell, T. J., Darby, A. P., and Everden, M., "Interpreting Conservativeness in Design Criteria for Flexural Strengthening of RC Structures Using Externally Bonded FRP," International Journal of Concrete Structures and Materials, Vol. 4, No. 1, 2010, pp. 25-36.

3. Ibrahim Ary, M. and Kang, T. H.-K., "Shear-Strengthening of Reinforced \& Prestressed Concrete Beams Using FRP: Part I - Review of Previous Research," International Journal of Concrete Structures and Materials, Vol. 6, No. 1, 2012.

4. Ibrahim Ary, M.,"Shear Strengthening of Prestressed Concrete I-Beams Using Carbon Fiber-Reinforced Polymers," Master's thesis, School of Civil Engineering and Environmental Science, The University of Oklahoma, Norman, 2011, 96 pp.

5. Triantafillou, T. C. and Antonopoulos, C. P., "Design of Concrete Flexural Members Strengthened in Shear with FRP," ASCE Journal of Composites for Construction, Vol. 4, No. 4, 2000, pp. 198-205.

6. Bousselham, A. and Chaallal, O., "Shear Strengthening of
Reinforced Concrete Beams with Fiber-Reinforced Polymer: Assessment of Influencing Parameters and Required Research," ACI Structural Journal, Vol. 101, No. 2, 2004, pp. 219-227.

7. Sas, G., Täljsten, B., Barros, J., Lima, J., and Carolin, A., "Are Available Models Reliable for Predicting the FRP Contribution to the Shear Resistance of RC Beams?," ASCE Journal of Composites for Construction, Vol. 13, No. 6, 2009, pp. 514534.

8. ACI Committee 318, "Building Code Requirements for Structural Concrete (ACI 318-08) and Commentary," American Concrete Institute, Farmington Hills, MI, 2008, 473 pp.

9. ASTM, "American Society for Testing and Materials Annual Book of ASTM Standards," Vol. 04.09, West Conshohocken, PA, 2008.

10. ACI Committee 440, "Guide for the Design and Construction of Externally Bonded FRP Systems for Strengthening Concrete Structures (ACI 440.2R-08)," American Concrete Institute, Farmington Hills, MI, 2008, 76 pp. 